\title{
Risk factors for fluctuations in corneal endothelial cell density (Review)
}

\author{
RENATA VAICIULIENE $^{1}$, NEDA RYLSKYTE ${ }^{2}$, GABIJA BAGUZYTE ${ }^{1}$ and VYTAUTAS JASINSKAS ${ }^{1}$ \\ ${ }^{1}$ Department of Ophthalmology, Medical Academy, Lithuanian University of Health Sciences, LT-50161 Kaunas; \\ ${ }^{2}$ Faculty of Medicine, Lithuanian University of Health Sciences, LT-44307 Kaunas, Lithuania
}

Received July 28, 2021; Accepted October 29, 2021

DOI: $10.3892 /$ etm.2021.11052

\begin{abstract}
The cornea is a transparent, avascular and abundantly innervated tissue through which light rays are transmitted to the retina. The innermost layer of the cornea, also known as the endothelium, consists of a single layer of polygonal endothelial cells that serve an important role in preserving corneal transparency and hydration. The average corneal endothelial cell density (ECD) is the highest at birth $\left(\sim 3,000\right.$ cells $\left./ \mathrm{mm}^{2}\right)$, which then decrease to $\sim 2,500$ cells $/ \mathrm{mm}^{2}$ at adulthood. These endothelial cells have limited regenerative potential and the minimum (critical) ECD required to maintain the pumping function of the endothelium is $400-500$ cells $/ \mathrm{mm}^{2}$. ECD $<$ the critical value can result in decreased corneal transparency, development of corneal edema and reduced visual acuity. The condition of the corneal endothelium can be influenced by a number of factors, including systemic diseases, such as diabetes or atherosclerosis, eye diseases, such as uveitis or dry eye disease (DED) and therapeutic ophthalmological interventions. The aim of the present article is to review the impact of the most common systemic disorders (pseudoexfoliation syndrome, diabetes mellitus, cardiovascular disease), eye diseases (DED, uveitis, glaucoma, intraocular lens dislocation) and widely performed ophthalmic interventions (cataract surgery, intraocular pressure-lowering surgeries) on corneal ECD.
\end{abstract}

\section{Contents}

1. Introduction

2. Impact of systemic disorders on corneal endothelial cells

3. Impact of the most common eye diseases on corneal endothelial cells

Correspondence to: Mrs. Renata Vaiciuliene, Department of Ophthalmology, Medical Academy, Lithuanian University of Health Sciences, 2 Eiveniu street, LT-50161 Kaunas, Lithuania

E-mail: renata.vaiciuliene@1smuni.lt

Key words: corneal endothelial cell density, cornea, glaucoma, uveitis, intraocular lens dislocation, cataract surgery
4. Impact of the most common ophthalmic interventions on corneal endothelial cells

5. Conclusions

\section{Introduction}

The cornea is a transparent, avascular and abundantly innervated tissue through which light rays are transmitted to the retina $(1,2)$. The cornea is composed of the following layers: Epithelium, anterior elastic lamina (Bowman's membrane), stroma, pre-Descemet's or Dua's layer, posterior elastic lamina (Descemet's membrane) and the endothelium $(1,3)$. The innermost layer of the cornea (the endothelium) is $\sim 5-\mu \mathrm{m}$ thick and consists of a single layer of polygonal, mainly hexagonal, endothelial cells $(1,2,4)$.

The endothelium is important for preserving corneal transparency and hydration (5). To maintain corneal hydration and transparency, endothelial cells perform a dual function, serving both as a passive barrier and as an active pump (1,2,5). Tight junction-associated proteins, such as the zonula occludens-1 protein, function as a barrier to inhibit the release of fluid from the aqueous humor $(1,2)$. $\mathrm{Na}^{+} / \mathrm{K}^{+}$-ATPase pumps are located in the plasma membrane of endothelial cells, which are responsible for active ion transport. Water molecules osmotically diffuse from the corneal stroma into the aqueous humor by following $\mathrm{Na}^{+}$, which serves to maintain adequate corneal hydration and transparency $(1,2,5)$.

The number of the endothelial cells progressively reduces over the course of life (6-8). The average corneal endothelial cell density $(\mathrm{ECD})$ is the highest at birth $\left(\sim 3,000\right.$ cells $\left./ \mathrm{mm}^{2}\right)$, which decreases to $\sim 2,500$ cells $/ \mathrm{mm}^{2}$ in adulthood $(5,6)$. It is generally accepted that the normal rate of endothelial cell loss (ECL) is $0.6 \%$ per year (5). This loss of endothelial cells induces compensatory changes in the remaining endothelial cells, which migrate, enlarge and become more heterogeneous $(5,6)$. Corneal endothelial cells have limited regenerative potential due to $G_{1}$-phase cell cycle arrest $(1,2)$. The minimal (critical) ECD required for maintaining the pump function of the endothelium is $400-500$ cells $/ \mathrm{mm}^{2}$ (5). ECD lower than this critical value can lead to decreased corneal transparency, development of corneal edema and decreased visual acuity $(2,6)$.

Due to the limited regeneration of the corneal endothelium and its importance for visual function, it is necessary to 
understand the conditions that can reduce ECD and to develop an appropriate strategy to preserve the corneal endothelium and prevent potential corneal blindness. It has been reported that corneal endothelial cells are particularly sensitive and can be damaged by a number of factors, including systemic disorders, eye diseases and ophthalmological interventions. The aim of the present review was to summarize and discuss the most recent information available in this research field.

\section{Impact of systemic disorders on corneal endothelial cells}

Pseudoexfoliation (PEX) syndrome. PEX syndrome is a form of systemic microfibrillopathy that is characterized by the production and accumulation of extracellular granular amyloid-like material in the body tissues, including the anterior chamber of the eye $(9,10)$. The prevalence of PEX syndrome increases with age, at $10-20 \%$ in individuals aged $\geq 60$ years and $\sim 40 \%$ in those aged $>80$ years (9). Amyloid-like material is classically found on the anterior lens capsule, pupillary border, non-pigmented ciliary epithelium, lens zonules and corneal endothelium $(9,10)$. However, the specific etiopathogenesis mechanism of PEX syndrome remains poorly understood. Previous molecular and biochemical studies revealed that both genetic and non-genetic factors are involved in the pathogenesis of this disease (11-13). The most important genetic factor in the pathogenesis of PEX syndrome was reported to be single-nucleotide polymorphisms in the coding region of the lysyl-oxidase-like 1 gene, which is responsible for cross-linking the protein elastin $(11,13)$. Furthermore, non-genetic factors, such as diet, infectious pathogens, ultraviolet light exposure, hypoxia, oxidative stress and inflammation, have also been reported to serve important roles (11). These factors facilitate the synthesis of pro-fibrotic cytokines (IL-6) and growth factors (TGF- $\beta 1$ ), disrupt the imbalance between MMPs and tissue inhibitor of metalloproteinases and promote the development of low-grade chronic inflammatory processes $(11,13)$. All these processes aforementioned have been documented to be involved in the pathological synthesis and accumulation of extracellular amyloid-like material $(9,11)$.

PEX has been known to cause damage to corneal endothelial cells. Tomaszewski et al (10) previously evaluated the ECD in patients with PEX syndrome, PEX glaucoma (PEXG) and a control group using specular microscopy. They found that the ECD was significantly lower in the PEX group compared with that in the control group $\left(2,297 \pm 359\right.$ cells $/ \mathrm{mm}^{2}$ vs. $2,503 \pm 262$ cells $/ \mathrm{mm}^{2}$, respectively). The ECD change in the PEXG group was also analyzed in this previous study. The obtained data revealed that the ECD in the PEXG group $\left(2,241 \pm 363\right.$ cells $\left./ \mathrm{mm}^{2}\right)$ was also significantly lower compared with that in the control group, but statistical significance could not be observed between the PEX and PEXG groups (10). A decrease in the ECD in patients with PEX syndrome has also been reported by other studies. In a study by Aoki et al (14), patients were classified into the mild, moderate and severe groups based on the quantity of PEX material deposits on the iris surface (14). The mean ECD was found to be significantly lower in all three PEX groups compared with that in the control group (14). It was also observed that the mean ECD in patients with mild and moderate PEX was significantly higher compared with that in the group of patients with severe
PEX (14). Therefore, ECD appears to depend on the severity of PEX and the accumulation of amyloid-like material. Currently, it is being proposed that PEX-associated damage to the corneal endothelium may be of multifactorial etiology. One of the existing hypotheses is that PEX material can settle on the corneal endothelium and penetrates it in the direction of the Descemet's membrane $(9,10)$. This then breaks the connections between hexagonal endothelial cells to activating a plethora of signaling pathways, which increases the synthesis of cytokines and chemokines $(9,10)$. Therefore, the local apoptosis of corneal endothelial cells is accelerated (10). In addition, the characteristic hexagonal shape and homogeneous size of the remaining cells are lost as part of the compensatory mechanism for the loss of endothelial cells (9).

Diabetes mellitus (DM). DM is a chronic, systemic metabolic disease that is caused by autoimmune insulin depletion or acquired insulin resistance (15-17). The World Health Organization global report on DM showed that the number of adults diagnosed with DM has almost quadrupled since 1980 to the current total of 422 million adults (16). Furthermore, it is estimated that $>555$ and $>640$ million individuals worldwide will suffer from DM by 2030 and 2040, respectively (15). There are two types of DM, both of which lead to chronic hyperglycemia and mediate damage to vital organs, such as the cardiovascular system, kidneys and anterior and posterior segments of the eye $(16,17)$. Although the most severe ophthalmological complication of DM is retinopathy, other corneal components, including the epithelium, stroma, nerves and endothelium, are also known to be affected by DM and poor glycemic control $(15,16,18)$.

The core initiating mechanism of ocular complications is hyperglycemia $(15,19)$. It increases the mitochondrial production of reactive oxygen species (ROS), causing strand breaks in the nuclear DNA and activation of poly(ADP-ribose) polymerase (PARP) (19). PARP then reduces the activity of the key glycolytic enzyme GAPDH, which finally leads to increased glucose flux through the polyol pathway, increased formation of intracellular advanced glycation end (AGE) products, activation of protein kinase $\mathrm{C}$ and $\mathrm{NF}-\kappa \mathrm{B}$ and increased hexosamine pathway flux $(15,19)$. This ROS accumulation also causes disruptions in the mitochondrial electron transport chain, which results in mitochondrial injury and likely causes changes to endothelial physiology in the cornea $(15,20)$. Accumulation of AGE products in the cornea has been documented to be localized to the laminin-rich epithelial basement membrane, where they promote crosslinking and decrease epithelial cell attachment (17). AGE-mediated crosslinking can also affect other proteins, such as myelin, laminin, heparan sulphate proteoglycan and tubulin, which can lead to defects in the basement membrane, endothelial barrier integrity and maintenance of the macro- and microvasculature (17). In addition, aggregation of AGE products may reduce the number of corneal endothelial cells and disrupt endothelial cell metabolism (20). Chronic hyperglycemia results in changes in ECD, central corneal thickness and hexagonality of endothelial cells, in addition to impairments in its pump function $(20,21)$. Elevated intracellular glucose levels can decrease $\mathrm{Na}^{+} / \mathrm{K}^{+}$-ATPase activity on the cell membrane to increase endothelial permeability $(15,21)$. Furthermore, loss of endothelial pump and epithelial barrier 
function, coupled with the crosslinking of stromal collagen and matrix, may cause corneal swelling (21). Previous studies reported no changes in the ECD in patients with DM (22-25), whilst subsequent studies found reduced numbers of endothelial cells in these patients $(16,18)$. Shih et al $(21)$ previously performed a systematic review on the impact of DM on the ocular surface, which found a statistically significant association between type $2 \mathrm{DM}$ and increased incidence of clinicopathological features of corneal endothelial dysfunction, including reduced endothelial count, polymegathism and pleomorphism. Additionally, other studies $(16,26,27)$ have also reported that the ECD is markedly lower in patients with DM. In particular, it appeared that the longer the patient was affected with DM, the greater the loss of endothelial cells (16). Similar findings were also observed by El-Agamy and Alsubaie (28), who found that ECD was significantly lower in the diabetic cornea group compared with that in the control group $\left(2,491.98 \pm 261.08\right.$ vs. 2,629.68 \pm 293.45 cells $\left./ \mathrm{mm}^{2}\right)$. Another study by Leelawongtawun et al (24) reported decreased ECD and percentages of hexagonal cells, along with increased percentages of polymegathism, in patients with DM compared with those in non-diabetic individuals. However, these findings were not statistically significant $(2,360 \pm 246$ vs. $2,413 \pm 314$ cells $/ \mathrm{mm}^{2}$ ) (24). An association between higher levels of haemoglobin A1c and lower ECD was also found, although it was also not statistically significant $(20,28)$. In terms of endothelial cell morphology, the number of endothelial cells with polymegathism and pleomorphism was also found to be significantly higher in patients with DM $(16,18,20)$. Furthermore, a significant correlation between the duration of $\mathrm{DM}$ and pleomorphism and polymegathism was previously demonstrated, suggesting an association between the duration of DM evolution and the extent or severity of endothelial alterations $(16,18,20)$. In particular, in patients with DM, tear secretion was frequently observed to be significantly lower and tear osmolarity is increased, leading to the higher incidence of dry eye, which is also known to lower $\operatorname{ECD}(15,18)$.

Cardiovascular disease. Despite the limited number of studies, available information suggests that endothelial dysfunction in the cornea and cardiovascular diseases may share similar characteristic. A study previously conducted by Gad et al (29) revealed corneal endothelial cell abnormalities in patients following transient ischemic attack and minor ischemic stroke. Khan et al (30) also demonstrated a reduction in the corneal ECD and increases in endothelial cell size in patients after acute ischemic stroke. In 2018, Scherer (31) conducted a global survey and correlative meta-analysis, in which 392 datasets (39,762 eyes) from 267 source studies were assigned to 42 countries. The results of this previous study revealed negative associations between ECD and mortality due to cardiovascular diseases (coronary artery disease and hypertension) on a population-based level (31).

Risk factors for cardiovascular disease, such as smoking and hyperlipidemia, are also associated with corneal endothelial cell dysfunction. Bu et al (32) mimicked the effect of hyperlipidemia on the physiology of corneal endothelial cells in an hyperlipidemia animal model, where $\mathrm{ApoE}^{-/-}$and wild-type mice were used. This previous study observed hyperlipidemia-induced cell junction damage and reduced pump function in corneal endothelial cells (32). In vivo confocal microscopy results also revealed a decreased percentage of the typical hexagonal endothelial cells in mice with hyperlipidemia (32). In addition, decreased ECD in the hyperlipidemic mice was observed, which was closely associated with the severity of hyperlipidemia (32). It was therefore concluded that hyperlipidemia may be a risk factor for corneal endothelial dysfunction (32). In a recent systematic review with meta-analysis, 18 studies with 2,077smokers and 6,429 non-smokers were evaluated (33). A lower ECD of -140 cells $/ \mathrm{mm}^{2}$ (95\% confidence interval, -30 to -250 cells $/ \mathrm{mm}^{2}$ ) was found in smokers compared with that in non-smokers (33). These results suggest that smoking-induced hypoxia and chronic low-grade systemic inflammation can potentially adversely affect corneal endothelial cells.

\section{Impact of the most common eye diseases on corneal endothelial cells}

Dry eye disease (DED). DED is a multifactorial disease of the tear film and ocular surface $(34,35)$. According to previous studies, the prevalence of DED varies from 5 to $50 \%$ (34-36). The causes of DED can be classified into external and internal factors. Age, female sex, presence of systemic autoimmune diseases and use of anticholinergic medications are considered to be internal factors (37). By contrast, living in a dry windy environment, contact lens usage, prolonged video display viewing and use of eye drops containing preservatives are considered to be external factors for DED (37). The interplay between these and other factors can cause tear film instability and tear hyperosmolarity, which in turn leads to the activation of stress signaling pathways in cells on the ocular surface and inflammation, resulting in the apoptosis of corneal epithelial cells $(37,38)$. Due to inflammation and cell apoptosis, barrier function of the corneal epithelium is disrupted, such that the quality of the tear film is reduced to cause instability of the tear film. This forms a closed, self-perpetuating vicious circle $(37,38)$. Furthermore, deeper layers of the cornea have also been suggested to be involved in DED. Kheirkhah et al (36) found that the ECD was significantly lower in patients in the DED group compared with those in the control group $(2,595.8 \pm 356.1$ vs. $2,812.7 \pm 395.2$ cells $/ \mathrm{mm}^{2}$ ). However, the precise mechanism underlying ECL remains to be fully elucidated. It is hypothesized that inflammation-induced reductions in the corneal sub-basal nerve density may be one possible mechanism $(35,36)$. Another study by Kheirkhah et al $(35)$ revealed that the corneal sub-basal nerve density was significantly lower in the DED group compared with that in the control group $\left(17.8 \pm 7.5\right.$ vs. $\left.22.8 \pm 3.0 \mathrm{~mm} / \mathrm{mm}^{2}\right)$. Decreased corneal sub-basal nerve density has been reported to impair the trophic function of the cornea, which disrupts endothelial cell function and survival $(35,36)$. By contrast, predominant DED-associated inflammation may lead to simultaneous reductions in the corneal sub-basal nerve density and corneal ECD $(34,36)$. Although inflammation typically results in the apoptosis of corneal epithelial cells, it has also been suggested that corneal stromal keratocytes may also be involved (36). Therefore, it was hypothesized that this inflammatory process may also involve the corneal endothelium (36). 
Uveitis. Uveitis is an intra-ocular inflammation of the uvea (iris, ciliary body and choroid) $(39,40)$. According to its etiology, uveitis can be categorized as infectious and non-infectious $(39,40)$. Infectious uveitis can be caused by bacteria, viruses, fungi or parasites, whilst non-infectious uveitis is typically associated with rheumatological and autoimmune diseases $(39,40)$. Regardless of the cause, chronic intraocular inflammation predominates in the pathogenesis of uveitis $(41,42)$. In particular, inflammatory cytokines circulating in the aqueous humor are considered to cause corneal endothelial cell damage (41).

Recent studies have shown that corneal ECD decreases in eyes with uveitis, particularly in those with anterior uveitis (43-45). Alfawaz et al (45) performed a study on the corneal endothelial cell variables among individuals with active or previous uveitis (anterior, anterior and intermediate, or panuveitis) in one or both eyes $(n=52)$. Endothelial variables were then compared with those in an age-matched control group $(n=43)$. The results of this previous study revealed that the mean central ECD was significantly lower in eyes with uveitis compared with that in eyes of the control group at each age interval (45). After excluding patients who had previously undergone surgical intervention (cataract or glaucoma surgery), the outcome remained unchanged (45). In addition, a significantly lower percentage of hexagonal endothelial cells was observed in eyes with uveitis compared with that in healthy eyes, where pleomorphism was not observed after surgical interventions (45). Subsequent univariate analysis revealed that, the longer the duration of active uveitis, the higher the intraocular pressure, higher observed level of anterior chamber flare and lower density of corneal ECD (45). Reductions in ECD has also been reported by other studies previously. Guclu and Gurlu (41) performed a cross-sectional study on 56 eyes of patients with inactive anterior uveitis and 53 eyes of healthy individuals. Statistical analysis revealed that the ECD was significantly lower in the uveitis group compared with that in the control group $\left(2,540 \pm 619\right.$ vs. $2,834 \pm 413$ cells $\left./ \mathrm{mm}^{2}\right)$. However, this previous study did not find significant correlations between ECD and the duration of uveitis or number of episodes.

According to the observations in the aforementioned studies, changes in ECD may be a result of direct damage by contact with inflammatory cells or the effect of inflammatory proteins, such as cytokines, in the aqueous humor $(41,45)$.

Glaucoma. Glaucoma is a chronic, progressive type of optic neuropathy that induces morphological changes or cell death in retinal ganglion cells and the nerve fiber layer (46). Glaucoma is one of the most common causes of blindness in Europe and worldwide $(47,48)$. A total of $\sim 66.8$ million individuals worldwide are reported to suffer from this disease, where its prevalence is on the increase $(47,48)$. This chronic disease is associated with progressive retinal ganglion cell death, narrowing of the visual field or even loss of vision, in addition to corneal ECD reduction $(46,47)$. The main cause of corneal damage during glaucoma is considered to be due to direct compression and hypoxia as a result of increased intraocular pressure (27). Proteins associated with oxidative stress, apoptosis and inflammation, including gelsolin, plasminogen, angiotensinogen, apolipoprotein A-II, $\beta$-2-microglobulin, dickkopf-3, pigment epithelium-derived factor, RIG-like 7-1, afamin, fibronectin 1, apolipoprotein A-I, activated complement $\mathrm{C} 4$ protein and prothrombin, were all found in the aqueous humor of patients with glaucoma (24). Yu et al (49) previously compared patients with primary open-angle glaucoma with healthy individual in a control case study, who observed that patients with primary open-angle glaucoma have significantly lower ECD compared with that in the healthy group.

Apart from the pathology of this disease, various forms of treatment for glaucoma can also exert adverse effects on the corneal endothelium (49). Topical medication is typically the first-line treatment option for glaucoma (50). Drugs that can reduce intraocular pressure are categorized into the following five main groups: i) Prostaglandin analogues, ii) $\beta$-blockers, iii) carbonic anhydrase inhibitors, iv) cholinergic agonists; and v) $\alpha$-agonists (48). Whilst treatment can lower intraocular pressure, long-term use of these preservatives can induce cell toxicity (51). This phenomenon has garnered the attention of researchers. However, direct associations between drugs used for treating glaucoma treatment and a reduction in ECD remain elusive $(49,51)$. Kwon et al (50) previously performed a study to evaluate the possible association between ECD and the donor use of topical glaucoma medications in the Lions Eye Institute Eye Bank of Tampa, Florida database.

The ECD of donors treated with topical medications was found to be comparable with that of untreated donors (50). In a subgroup analysis by drug class, no significant differences in ECD could be found between untreated donors and donors treated with $\alpha$-agonists, $\beta$-blockers, carbonic anhydrase inhibitors, cholinergic agonists or prostaglandin analogues (50).

Intraocular lens (IOL) dislocation. A late spontaneous 'in-the-bag' IOL dislocation is one of the most serious complications that occur after lens stability is disturbed due to decompensation of the Zinn's zonule $(50,52)$. The low incidence rate of these complications $(50,52,53)$ has a potential to increase in the future due to the increased pseudophakic population as a result of improvements in the safety and quality of cataract surgery $(54)$, increased cataract surgery rate $(55,56)$ and economic development (57). IOL dislocation can be the cause of diplopia, worsening visual acuity and increased intraocular pressure, which can cause damage to the iris and corneal endothelial cells $(58,59)$.

Vaiciuliene and Jasinskas (60) previously a prospective study involving 78 patients with IOL dislocation. A total of 80 eyes were divided into four grades according to the in-the-bag IOL dislocation classification (61). ECD was evaluated using in vivo corneal confocal microscopy (61). The median corneal ECD of all the eyes was 1,929 cells $/ \mathrm{mm}^{2}$ (range, $\left.1,022-2,958\right)(61)$. In a randomized study, Kristianslund et al (62) previously compared two different dislocated IOL treatment options (first group: The Intraocular lens-capsule complex was replaced with a retropupillary iris-claw intraocular lens; second group: Re-suturing of the haptics to the scleral wall), and showed that the mean baseline ECD was $1,940 \pm 418$ cells $/ \mathrm{mm}^{2}$ in the first group and $1,718 \pm 449$ cells $/ \mathrm{mm}^{2}$ in the second group. Similar data (mean ECD, $1,778.5 \pm 775.6$ cells $/ \mathrm{mm}^{2}$ in the IOL refixation group and $2,070.4 \pm 458.8$ cells $/ \mathrm{mm}^{2}$ in the IOL exchange group) were also reported by Eum et al (63). 
Surgery for IOL dislocation treatment involves IOL exchange or repositioning and fixation to the sclera or iris (62-65). The latter surgical intervention is classified as a minimally invasive surgery $(62,65)$. The difference between IOL repositioning/fixation and IOL exchange is important for consideration in patients already with a compromised corneal endothelium prior to IOL dislocation surgery, because there is a higher risk of ECL after IOL replacement (62). In a randomized clinical trial comparing lens repositioning and lens exchange, Kristianslund et al (62) previously found a non-significant postoperative ECD loss of 3\% in the repositioning group and a significant postoperative ECD loss of $10 \%$ in the exchange group 6 months after surgery compared with those in the lens repositioning group.

In conclusion, late spontaneous in-the-bag IOL dislocation appears to have an impact on the reduction of corneal ECD. Therefore, attention should be paid to the condition of the endothelium before selecting a particular surgical treatment strategy.

\section{Impact of the most common ophthalmic interventions on corneal endothelial cells}

Cataract surgery. Cataracts is characterized by an opacification of the normally transparent crystalline lens, resulting in visual impairment $(66,67)$. Although this disease can now be successfully treated surgically, cataract remains to be the leading cause of blindness and a secondary cause of moderate to severe vision impairment worldwide (58). Improvements in cataract surgical treatment, including the development of original techniques and advancements in instrumentation, has rendered this type of surgery less traumatic and more capable of rapidly restoring visual acuity (66). Therefore, in numerous developed countries, cataracts surgery remains to be one of the most commonly performed surgical procedures, providing significant, long-term and cost-effective improvements to the quality of life of patients (58). At present, the gold standard of cataract surgery is phacoemulsification using a clear corneal incision (66). Compared with other older cataract surgical procedures, phacoemulsification is considered to be the safest form of intervention, since only a small incision is required during phacoemulsification surgery and results in a lower risk of perioperative complications and increased rate of rehabilitation (66). However, despite all the advantages, cataract phacoemulsification can cause a significant reduction in the number of corneal endothelial cells $(6,68,69)$.

Factors affecting corneal endothelial damage during phacoemulsification can be classified into modifiable and non-modifiable factors (6). The degree of nucleus opalescence, depth of the anterior chamber of the eye and axial length of the eye are considered non-modifiable risk factors, whilst phacoemulsification time and ultrasound (US) power, surgical instrument-related trauma, type of ophthalmic viscoelastic devices (OVDs) and turbulence of fluids in the anterior chamber of the eye are considered to be modifiable risk factors $(6,69)$. The high-intensity US energy used during cataract phacoemulsification for the fragmentation and emulsification of the lens is considered to be an important cause of corneal ECL $(68,70)$. The oscillation of US waves in an aqueous solution has been reported to cause a phenomenon known as acoustic cavitation, which is the formation and subsequent collapse of vapor- or gas-filled bubbles in the liquid (68). The development of bubbles is caused by a local pressure decrease in the aqueous humor, whereas the bursting of the bubbles is caused by an increase in pressure (68). The collapse of gas bubbles generates micro-shockwaves, leading to a local increase in pressure and temperature and can result in the direct dissociation of water molecules (68). Water molecules then dissociate into hydrogen and hydroxyl radicals, which are amongst the most reactive of the ROS that can cause oxidative stress in endothelial cells (68). Igarashi et al (68) previously performed a study on porcine and rabbit model in which the level of free hydroxyl radicals in the anterior chamber of the model eye was measured following phacoemulsification. It was demonstrated that these types of free radicals can mediate oxidative stress damage to the corneal endothelium (68). It has been reported that phacoemulsification-induced corneal ECL occurs in two phases (69). During the first phase, which takes place within the first week after cataract surgery, a variable decrease in ECD occurs, which is dependent on the degree of the surgical instrument-related trauma (69). The second phase typically begins later and lasts for $\geq 10$ years after surgery (69). During this period, the ECD decreases at a rate of $2.5 \%$ per year, which is four-fold higher compared with that under normal physiological conditions (69). The exact cause of long-term ECL after cataract phacoemulsification remain poorly understood. Choi and Han (69) hypothesized that prolonged ECL after cataract surgery is associated with the remodeling of the corneal endothelium. However no statistically significant differences could be found in endothelial cell hexagonality or coefficient of variation before and after surgery (69). However, this accelerated ECL after cataract surgery is likely to be a process of chronic cell loss rather than prolonged remodeling (69). The causes of this chronic cell loss may include decreased nutrition from the aqueous humor, increased sub-clinical inflammation, decreased innervation and exposure to vitreous humor $(8,69)$. Short and long-term changes in the corneal ECD after phacoemulsification have been reported by recent studies. Bamdad et al (67) performed a prospective study involving 85 patients and 92 eyes diagnosed with immature senile cataract. The corneal ECD was measured before surgery and four times after surgery (after 1 day, 1 week, 1 and 3 months) (67). It was found that after cataract phacoemulsification, the corneal ECD decreased from $2,791.15 \pm 99.86$ to $2,472.87 \pm 472.14$ cells $/ \mathrm{mm}^{2}$, which is $11.4 \%$ (67). By contrast, the long-term ( $>10$ years since cataract surgery) changes observed in ECD were found to be even greater. Choi and Han (69) demonstrated that the mean 10-year ECD decreased from 2,793.2 \pm 351.1 to $2,148.04 \pm 478.38$ cells $/ \mathrm{mm}^{2}$, which is $20.62 \pm 13.63 \%$. Furthermore, significant risk factors for postoperative corneal ECL were identified to be preoperative nuclear firmness grade and postoperative corneal edema (69). Under the influence of these factors, the corneal ECD was found to decrease more rapidly (69).

Although phacoemulsification is the gold standard of cataract surgical treatment, manual small-incision cataract surgery (MSICS) is also a viable cost-effective alternative to phacoemulsification in developing countries (71). In addition, MSICS can be applied on hyper-mature and cloudy cataracts (a white 
cataract) (71-73). In MSICS, the entire lens is removed through a self-sealing scleral tunnel incision $(5-7 \mathrm{~mm})$ and an intraocular lens is then implanted into the capsular bag (72). Although MSICS requires a much bigger incision compared with that of phacoemulsification, the ECL and visual outcomes are similar in both cases (74). A meta-analysis previously performed by Gogate et al (72) revealed similar ECL after phacoemulsification and MSICS (odds ratio: 1.00; 95\% confidence interval: -0.89 to 2.90$)$. By contrast, Ganekal and Nagarajappa (71) found a statistically significant decrease in ECD in the MSICS group compared with that in the phacoemulsification group. Increased ECL after MSICS is mainly associated with surgical manipulations in the anterior chamber and endothelial trauma during nucleus extraction through the anterior chamber (71). Modern cataract surgery uses OVDs, which offer corneal endothelial protection (70). In a previous study using pig eyes, Yildirim et al (70) demonstrated that the postoperative ECD of corneas after treatment with dispersive OVDs was higher compared with that of corneas treated with cohesive OVDs. The authors concluded that the use of dispersive OVDs can protect the corneal endothelium during phacoemulsification in a superior manner compared with cohesive OVDs.

A relatively new technology that has one of the advantages of protecting endothelial cells by reducing the US, which is due to the automation of nuclear fragmentation, is femtosecond laser-assisted cataract surgery (75). However, the reported findings on this technique have been controversial. Results from a meta-analysis conducted in 2016 involving 14,567 eyes revealed that femtosecond laser-assisted cataract surgery is safer for the corneal endothelium compared with conventional manual cataract surgery (75). However, the results of recent randomized studies do not indicate statistically significant differences in the corneal endothelium parameters between femtosecond laser-assisted cataract surgery and conventional cataract surgery (76-78).

Intraocular pressure-lowering surgeries. Intraocular pressure-lowering surgeries are typically conducted on patients with serious or uncontrolled glaucoma (79). Gradual decline in ECD, which can be accompanied with corneal decompensation, is one of the potential side effects of glaucoma surgery (79). Trabeculectomy is considered to be the gold standard for reducing intraocular pressure (48). Hirooka et al (80) conducted a prospective study that followed 117 eyes of 117 patients for 2 years after trabeculectomy. It was found that the corneal ECD was significantly decreased, which continued after surgery (80). At 6, 12, 18 and 24 months after surgery, the loss of ECD was $91,85,83$ and $77 \%$, respectively, of the baseline value (80). To investigate the effect of combined phacotrabeculectomy, trabeculectomy and phacoemulsification on the corneal endothelium, Demir et al (81) performed a prospective study. They found postoperative reductions in the corneal ECD of each of the three aforementioned groups compared with that in the preoperative period $(6.1 \%$ in the phacotrabeculectomy group, $4.9 \%$ in the trabeculectomy group and $7.4 \%$ in the phacoemulsification group) (81). It was therefore concluded that performing combined phacotrabeculectomy did not damage the corneal endothelium more than other surgical methods (81). Another previous 2-year follow-up study found that after Ahmed's valve surgery, the reduction in ECD averaged $18.6 \%$ at 24 months after surgery, with the majority of cells being lost in the upper temporal quadrant (22.6\%) (82). This decrease is a clinically important finding, since corneal decompensation is the most common complication after Ahmed's valve surgery, which was found in $27 \%$ of the operated eyes (75). Kim et al (83) found that tubular shunts are more damaging to the endothelium compared with the effects mediated by trabeculectomy. At 12 months after Ahmed's valve implantation, the reduction in ECD was $12.3 \%$ vs. after trabeculectomy, where the reduction was $3.2 \%$ (83). Although the same postoperative intraocular pressure was achieved after both procedures, the risk of endothelial damage was significantly different (83). To evaluate the impact of EX-PRESS device implantation on ECD, Casini et al (84) compared this technique with trabeculectomy and Ahmed's valve implantation for the treatment of primary open-angle glaucoma in a prospective study. The results showed no change in ECD in patients who underwent EX-PRESS implantation at 1 or 3 months after surgery (84). By contrast, in the trabeculectomy group, the ECD significantly decreased by $3.5 \%$ at 1 month and then by $4.2 \%$ at 3 months after the procedure (84). In the subjects who underwent Ahmed's valve implantation treatment, the ECD did not change at 1 month after treatment but significantly decreased by $3.5 \%$ at 3 months (84). In conclusion, EX-PRESS device implantation surgery was proposed to be a safer procedure regarding the risk of decreasing ECD.

Another therapeutic procedure that has been used for the management of glaucoma is selective laser trabeculoplasty (79). Although the side effects associated with this procedure, such as corneal edema, are rare and relatively temporary, corneal endothelial cells may be affected because the trabecular meshwork can be reached by the laser energy traversing the cornea (79). Kanagaratnam and Ong (85) performed a study to evaluate the potential damage caused by selective laser trabeculoplasty. The results showed statistically significant recovery at 1 month after selective laser trabeculoplasty (85). It was therefore proposed that this procedure has measurable yet transient effects on the morphological characteristics of the corneal endothelium (85).

Patients with glaucoma are at high risk of damage to the corneal endothelial cells. Therefore, objective glaucoma data and corneal ECD should be evaluated before the selection of treatment strategies.

\section{Conclusions}

Despite its limitations, the present review has demonstrated a clear association between corneal ECD alterations and the most common eye diseases, systematic diseases and ophthalmological interventions. Therefore, it can be concluded that ECD is an important indicator that reflects the condition of the cornea and requires particular consideration in patients with chronic eye diseases, such as recurrent uveitis, glaucoma and PEX, in addition to patients with IOL dislocation and before each ophthalmological intervention.

\section{Acknowledgements}

Not applicable. 


\section{Funding}

No funding was received.

\section{Availability of data and materials}

Not applicable.

\section{Authors' contributions}

$\mathrm{RV}, \mathrm{NR}, \mathrm{GB}$ and VJ were involved in the conceptualization and writing of the manuscript. Data authentication is not applicable. All authors read and approved the final manuscript.

\section{Ethics approval and consent to participate}

Not applicable.

\section{Patient consent for publication}

Not applicable.

\section{Competing interests}

The authors declare that they have no competing interests.

\section{References}

1. Feizi S: Corneal endothelial cell dysfunction: Etiologies and management. Ther Adv Ophthalmol 10: 2515841418815802, 2018

2. Price MO, Mehta JS, Jurkunas UV and Price FW Jr: Corneal endothelial dysfunction: Evolving understanding and treatment options. Prog Retin Eye Res 82: 100904, 2021.

3. Dua HS, Faraj LA, Said DG, Gray T and Lowe J: Human corneal anatomy redefined: A novel pre-Descemet's layer (Dua's layer). Ophthalmology 120: 1778-1785, 2013.

4. Abdellah MM, Ammar HG, Anbar M, Mostafa EM, Farouk MM, Sayed K, Alsmman AH and Elghobaier MG: Corneal endothelial cell density and morphology in healthy egyptian eyes. J Ophthalmol 2019: 6370241,2019.

5. Ewete T, Ani EU and Alabi AS: Normal corneal endothelial cell density in Nigerians. Clin Ophthalmol 10: 497-501, 2016.

6. Khalid M, Ameen SS, Ayub N and Mehboob MA: Effects of anterior chamber depth and axial length on corneal endothelial cell density after phacoemulsification. Pak J Med Sci 35: 200-204, 2019.

7. Tuft SJ and Coster DJ: The corneal endothelium. Eye (Lond) 4 (Pt 3): 389-424, 1990

8. Bourne WM: Biology of the corneal endothelium in health and disease. Eye (Lond) 17: 912-918, 2003.

9. Palko JR, Qi O and Sheybani A: Corneal alterations associated with pseudoexfoliation syndrome and glaucoma: A literature review. J Ophthalmic Vis Res 12: 312-324, 2017.

10. Tomaszewski BT, Zalewska R and Mariak Z: Evaluation of the endothelial cell density and the central corneal thickness in pseudoexfoliation syndrome and pseudoexfoliation glaucoma. J Ophthalmol 2014: 123683, 2014.

11. Andrikopoulos GK, Alexopoulos DK and Gartaganis SP Pseudoexfoliation syndrome and cardiovascular diseases. World J Cardiol 6: 847-854, 2014.

12. Thorleifsson G, Magnusson KP, Sulem P, Walters GB, Gudbjartsson DF, Stefansson H, Jonsson T, Jonasdottir A, Jonasdottir A, Stefansdottir G, et al: Common sequence variants in the LOXL1 gene confer susceptibility to exfoliation glaucoma. Science 317: 1397-1400, 2007.

13. Schlötzer-Schrehardt U: Pseudoexfoliation syndrome: The puzzle continues. J Ophthalmic Vis Res 7: 187-189, 2012.

14. Aoki T, Kitazawa K, Inatomi T, Kusada N, Horiuchi N, Takeda K Yokoi N, Kinoshita S and Sotozono C: Risk factors for corneal endothelial cell loss in patients with pseudoexfoliation syndrome. Sci Rep 10: 7260, 2020.
15. Han SB, Yang HK and Hyon JY: Influence of diabetes mellitus on anterior segment of the eye. Clin Interv Aging 14: 53-63, 2018.

16. Del Buey MA, Casas P, Caramello C, López N, de la Rica M, Subirón AB, Lanchares E, Huerva V, Grzybowski A and Ascaso FJ: An update on Corneal biomechanics and architecture in diabetes. J Ophthalmol 2019: 7645352, 2019.

17. McKay TB, Priyadarsini S and Karamichos D: Mechanisms of collagen crosslinking in diabetes and keratoconus. Cells 8: 1239 , 2019.

18. Ljubimov AV: Diabetic complications in the cornea. Vision Res 139: 138-152, 2017.

19. Brownlee M: The pathobiology of diabetic complications: A unifying mechanism. Diabetes 54: 1615-1625, 2005.

20. Zhao H, He Y, Ren YR and Chen BH: Corneal alteration and pathogenesis in diabetes mellitus. Int J Ophthalmol 12: 1939-1950, 2019

21. Shih KC, Lam KS and Tong L: A systematic review on the impact of diabetes mellitus on the ocular surface. Nutr Diabetes 7: e251, 2017.

22. Matsuda M, Ohguro N, Ishimoto I and Fukuda M: Relationship of corneal endothelial morphology to diabetic retinopathy, duration of diabetes and glycemic control. Jpn J Ophthalmol 34: 53-56, 1990.

23. Larsson LI, Bourne WM, Pach JM and Brubaker RF: Structure and function of the corneal endothelium in diabetes mellitus type I and II. Arch Ophthalmol 114: 9-14, 1996.

24. Leelawongtaw un W, Suphachearaphan W, Kampitak K and Leelawongtawun R: A comparative study of corneal endothelial structure between diabetes and non-diabetes. J Med Assoc Thai 98: 484-488, 2015.

25. Storr-Paulsen A, Singh A, Jeppesen H, Norregaard JC and Thulesen J: Corneal endothelial morphology and central thickness in patients with type II diabetes mellitus. Acta Ophthalmol 92: 158-160, 2014.

26. Liaboe CA, Aldrich BT, Carter PC, Skeie JM, Burckart KA, Schmidt GA, Reed CR, Zimmerman MB and Greiner MA: Assessing the impact of Diabetes Mellitus on Donor Corneal Endothelial Cell Density. Cornea 36: 561-566, 2017.

27. Zhang K, Zhao L, Zhu C, Nan W, Ding X, Dong Y and Zhao M: The effect of diabetes on corneal endothelium: A meta-analysis. BMC Ophthalmol 21: 78, 2021.

28. El-Agamy A and Alsubaie S: Corneal endothelium and central corneal thickness changes in type 2 diabetes mellitus. Clin Ophthalmol 11: 481-486, 2017.

29. Gad H, Khan A, Akhtar N, Kamran S, El-Sotouhy A, Dargham SR, Petropoulos IN, Ponirakis G, Shuaib A, Streletz LJ and Malik RA: Corneal nerve and endothelial cell damage in patients with transient ischemic attack and minor ischemic stroke. PLoS One 14: e0213319, 2019.

30. Khan A, Kamran S, Akhtar N, Ponirakis G, Al-Muhannadi H, Petropoulos IN, Al-Fahdawi S, Qahwaji R, Sartaj F, Babu B, et al: Corneal confocal microscopy detects a reduction in corneal endothelial cells and nerve fibres in patients with acute ischemic stroke. Sci Rep 8: 17333, 2018.

31. Scherer WJ: Corneal endothelial cell density and cardiovascular mortality: A global survey and correlative meta-analysis. Clin Anat 31: 927-936, 2018

32. Bu J, Yu J, Wu Y, Cai X, Li K, Tang L, Jiang N, Jeyalatha MV, Zhang M, Sun H, et al: Hyperlipidemia affects tight junctions and pump function in the corneal endothelium. Am J Pathol 190: 563-576, 2020.

33. Frifelt LEW, Subhi Y, Holm LM and Singh A: Impact of tobacco use on corneal thickness and endothelial health: A systematic review with meta-analyses. Acta Ophthalmol: May 21, 2021 (Epub ahead of print). doi: 10.1111/aos.14897.

34. Villatoro AJ, Fernández V, Claros S, Alcoholado C, Cifuentes M, Merayo-Lloves J, Andrades JA and Becerra J: Regenerative therapies in dry eye disease: From growth factors to cell therapy. Int J Mol Sci 18: 2264, 2017.

35. Kheirkhah A, Satitpitakul V, Hamrah P and Dana R: Patients with dry eye disease and low subbasal nerve density are at high risk for accelerated corneal endothelial cell loss. Cornea 36: 196-201, 2017.

36. Kheirkhah A, Saboo US, Abud TB, Dohlman TH, Arnoldner MA, Hamrah P and Dana R: Reduced corneal endothelial cell density in patients with dry eye disease. Am J Ophthalmol 159: 1022-1026.e2, 2015.

37. Pflugfelder SC and de Paiva CS: The pathophysiology of dry eye disease: What we know and future directions for research. Ophthalmology 124 (Suppl 11): S4-S13, 2017. 
38. Baudouin C, Messmer EM, Aragona P, Geerling G, Akova YA, Benítez-del-Castillo J, Boboridis KG, Merayo-Lloves J, Rolando $\mathrm{M}$ and Labetoulle $\mathrm{M}$ : Revisiting the vicious circle of dry eye disease: A focus on the pathophysiology of meibomian gland dysfunction. Br J Ophthalmol 100: 300-306, 2016.

39. Rosenbaum JT, Bodaghi B, Couto C, Zierhut M, Acharya N, Pavesio C, Tay-Kearney ML, Neri P, Douglas K, Pathai S, et al: New observations and emerging ideas in diagnosis and management of non-infectious uveitis: A review. Semin Arthritis Rheum 49: 438-445, 2019.

40. Hsu YR, Huang JC, Tao Y, Kaburaki T, Lee CS, Lin TC, Hsu CC, Chiou SH and Hwang DK: Noninfectious uveitis in the Asia-Pacific region. Eye (Lond) 33: 66-77, 2019.

41. Guclu H and Gurlu V: Comparison of corneal endothelial cell analysis in patients with uveitis and healthy subjects. Int Ophthalmol 39: 287-294, 2019.

42. Trinh L, Brignole-Baudouin F, Labbé A, Raphaël M, Bourges JL and Baudouin C: The corneal endothelium in an endotoxin-induced uveitis model: Correlation between in vivo confocal microscopy and immunohistochemistry. Mol Vis 14: 1149-1156, 2008

43. Setälä K: Corneal endothelial cell density in iridocyclitis. Acta Ophthalmol (Copenh) 57: 277-286, 1979.

44. Ghită AC, Ilie L and Ghiță AM: The effects of inflammation and anti-inflammatory treatment on corneal endothelium in acute anterior uveitis. Rom J Ophthalmol 63: 161-165, 2019.

45. Alfawaz AM, Holland GN, Yu F, Margolis MS, Giaconi JA and Aldave AJ: Corneal endothelium in patients with anterior uveitis. Ophthalmology 123: 1637-1645, 2016.

46. European Glaucoma Society: Chapter 2: Classification and Terminology. In: Terminology and Guidelines for Glaucoma 4th edition. European Glaucoma Society Terminology and Guidelines for Glaucoma, pp 79, 2014.

47. McMonnies CW: Glaucoma history and risk factors. J Optom 10: 71-78, 2017.

48. Conlon R, Saheb H and Ahmed II: Glaucoma treatment trends: A review. Can J Ophthalmol 52: 114-124, 2017.

49. Yu ZY, Wu L and Qu B: Changes in corneal endothelial cell density in patients with primary open-angle glaucoma. World J Clin Cases 7: 1978-1985, 2019.

50. Kwon JW, Rand GM, Cho KJ, Gore PK, McCartney MD and Chuck RS: Association between corneal endothelial cell density and topical glaucoma medication use in an eye bank donor population. Cornea 35: 1533-1536, 2016.

51. Realini T, Gupta PK, Radcliffe NM, Garg S, Wiley WF, Yeu E, Berdahl JP and Kahook MY: The effects of glaucoma and glaucoma therapies on corneal endothelial cell density. J Glaucoma 30: 209-218, 2021.

52. Dabrowska-Kloda K, Kloda T, Boudiaf S, Jakobsson G and Stenevi U: Incidence and risk factors of late in-the-bag intraocular lens dislocation: Evaluation of 140 eyes between 1992 and 2012. J Cataract Refract Surg 41: 1376-1382, 2015

53. Østern AE, Sandvik GF and Drolsum L: Late in-the-bag intraocular lens dislocation in eyes with pseudoexfoliation syndrome. Acta Ophthalmol 92: 184-191, 2014.

54. Jakobsson G, Zetterberg M, Lundström M, Stenevi U, Grenmark R and Sundelin K: Late dislocation of in-the-bag and out-of-the bag intraocular lenses: Ocular and surgical characteristics and time to lens repositioning. J Cataract Refract Surg 36: 1637-1644, 2010.

55. Ascaso FJ, Huerva V and Grzybowski A: Epidemiology, etiology, and prevention of late IOL-capsular bag complex dislocation: Review of the literature. J Ophthalmol 2015: 805706, 2015.

56. Schein OD, Cassard SD, Tielsch JM and Gower EW: Cataract surgery among Medicare beneficiaries. Ophthalmic Epidemiol 19: 257-264, 2012

57. Behndig A, Montan P, Stenevi U, Kugelberg M and Lundström M: One million cataract surgeries: Swedish National Cataract Register 1992-2009. J Cataract Refract Surg 37: 1539-1545, 2011.

58. Wang W, Yan W, Fotis K, Prasad NM, Lansingh VC, Taylor HR, Finger RP, Facciolo D and He M: Cataract surgical rate and socioeconomics: A global study. Invest Ophthalmol Vis Sci 57: $5872-5881,2016$

59. Sousa DC, Leal I, Faria MY and Pinto LA: A rare manifestation of uveitis-glaucoma-hyphema syndrome. J Curr Glaucoma Pract 10: 76-78, 2016

60. Vaiciuliene R and Jasinskas V: Corneal endothelial status in different grades of late spontaneous in-the-bag IOL dislocation. Int Ophthalmol 41: 1625-1634, 2021

61. Shingleton BJ, Yang Y and O'Donoghue MW: Management and outcomes of intraocular lens dislocation in patients with pseudoexfoliation. J Cataract Refract Surg 39: 984-993, 2013.
62. Kristianslund O, Råen M, Østern AE and Drolsum L: Late in-the-bag intraocular lens dislocation: A randomized clinical trial comparing lens repositioning and lens exchange. Ophthalmology 124: 151-159, 2017.

63. Eum SJ, Kim MJ and Kim HK: A comparison of clinical outcomes of dislocated intraocular lens fixation between in situ refixation and conventional exchange technique combined with vitrectomy. J Ophthalmol 2016: 5942687, 2016.

64. Bulnes BL, de Rojas Silva MV and Moore RL: Intraocular pressure changes before and after surgery for spontaneous in-the-bag intraocular lens dislocation. J Cataract Refract Surg 45: 305-311, 2019.

65. Jasinskas V, Vaiciuliene R, Varoniukaite A and Speckauskas M: Novel microsurgical management of uveitis-glaucoma-hyphema syndrome. Int Ophthalmol 39: 1607-1612, 2019.

66. Jin C, Chen X, Law A, Kang Y, Wang X, Xu W and Yao K: Different-sized incisions for phacoemulsification in age-related cataract. Cochrane Database Syst Rev 9: CD010510, 2017.

67. Bamdad S, Bolkheir A, Sedaghat MR and Motamed M: Changes in corneal thickness and corneal endothelial cell density after phacoemulsification cataract surgery: A double-blind randomized trial. Electron Physician 10: 6616-6623, 2018.

68. Igarashi T, Ohsawa I, Kobayashi M,Igarashi T, Suzuki H, Iketani M and Takahashi H: Hydrogen prevents corneal endothelial damage in phacoemulsification cataract surgery. Sci Rep 6: 31190, 2016.

69. Choi JY and Han YK: Long-term ( $\geq 10$ years) results of corneal endothelial cell loss after cataract surgery. Can J Ophthalmol 54: 438-444, 2019

70. Yildirim TM, Auffarth GU, Son HS, Khoramnia R, Munro DJ and Merz PR: Dispersive viscosurgical devices demonstrate greater efficacy in protecting corneal endothelium in vitro. BMJ Open Ophthalmol 4: e000227, 2019.

71. Ganekal S and Nagarajappa A: Comparison of morphological and functional endothelial cell changes after cataract surgery: Phacoemulsification versus manual small-incision cataract surgery. Middle East Afr J Ophthalmol 21: 56-60, 2014.

72. Gogate P, Optom JJ, Deshpande S and Naidoo K: Meta-analysis to compare the safety and efficacy of manual small incision cataract surgery and phacoemulsification. Middle East Afr J Opht halmol 22: 362-369, 2015

73. Kongsap P: Central corneal thickness changes following manual small incision cataract surgery versus phacoemulsification for white cataract. Rom J Ophthalmol 63: 61-67, 2019.

74. Rosado-Adames $\mathrm{N}$ and Afshari NA: The changing fate of the corneal endothelium in cataract surgery. Curr Opin Ophthalmol 23: 3-6, 2012.

75. Popovic M, Campos-Möller X, Schlenker MB and Ahmed II: Efficacy and safety of femtosecond laser-assisted cataract surgery compared with manual cataract surgery: A meta-analysis of 14567 eyes. Ophthalmology 123: 2113-2126, 2016.

76. Day AC, Burr JM, Bennett K, Bunce C, Doré CJ, Rubin GS, Nanavaty MA, Balaggan KS and Wilkins MR; FACT group: Femtosecond laser-assisted cataract surgery versus phacoemulsification cataract surgery (FACT): A randomized noninferiority trial. Ophthalmology 127: 1012-1019, 2020.

77. Bascaran L, Alberdi T, Martinez-Soroa I, Sarasqueta C and Mendicute J: Differences in energy and corneal endothelium between femtosecond laser-assisted and conventional cataract surgeries: Prospective, intraindividual, randomized controlled trial. Int J Ophthalmol 11: 1308-1316, 2018.

78. Roberts HW, Wagh VK, Sullivan DL, Hidzheva P, Detesan DI, Heemraz BS, Sparrow JM and O'Brart DPS: A randomized controlled trial comparing femtosecond laser-assisted cataract surgery versus conventional phacoemulsification surgery. J Cataract Refract Surg 45: 11-20, 2019.

79. Janson BJ, Alward WL, Kwon YH, Bettis DI, Fingert JH, Provencher LM, Goins KM, Wagoner MD and Greiner MA: Glaucoma-associated corneal endothelial cell damage: A review. Surv Ophthalmol 63: 500-506, 2018.

80. Hirooka K, Nitta E, Ukegawa K, Sato S and Kiuchi Y Effect of trabeculectomy on corneal endothelial cell loss. $\mathrm{Br}$ J Ophthalmol 104: 376-380, 2020.

81. Demir AG, Olgun A, Guven D, Demir M, Sendul SY, Akarsu Acar OP and Kacar H: The effect of combined phacotrabeculectomy, trabeculectomy and phacoemulsification on the corneal endothelium in the early stage: A preliminary study. Int Ophthalmol 39: 2121-2128, 2019.

82. Lee EK, Yun YJ, Lee JE, Yim JH and Kim CS: Changes in corneal endothelial cells after Ahmed glaucoma valve implantation: 2-year follow-up. Am J Ophthalmol 148: 361-367, 2009 
83. Kim MS, Kim KN and Kim CS: Changes in corneal endothelial cell after ahmed glaucoma valve implantation and trabeculectomy: 1-year follow-up. Korean J Ophthalmol 30: 416-425, 2016.

84. Casini G, Loiudice P, Pellegrini M, Sframeli AT, Martinelli P, Passani A and Nardi M: Trabeculectomy versus ex-press shunt versus ahmed valve implant: Short-term effects on corneal endothelial cells. Am J Ophthalmol 160: 1185-1190. e1, 2015.
85. Kanagaratnam A and Ong K: Quantitative and morphological corneal endothelial changes after selective laser trabeculoplasty and retinal photocoagulation. Asia Pac J Ophthalmol (Phila) 9: 20-24, 2020.

c) (7) $\odot$ This work is licensed under a Creative Commons c. ${ }_{\text {EY NC ND }}$ Attribution-NonCommercial-NoDerivatives 4.0 International (CC BY-NC-ND 4.0) License. 